\title{
Algumas mãos de pintura
}

\section{LORENZO MAMMİ}

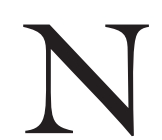

ESSES ÚLTIMOS ANOS, o interesse de curadores e instituições internacionais esteve bastante afastado da pintura. Meios que pressupõem um maior distanciamento da matéria e do gesto individual - fotografia, vídeo, instalação, e os assim chamados mixed media -, pareceram atrair muito mais a reflexão teórica. No entanto, nesses mesmos anos, o Brasil (e sobretudo, até onde eu sei, São Paulo) assistiu ao desenvolvimento de uma produção pictórica importante. Na década de 90, a pintura paulista fixou algumas questões que já esboçara no final da década passada, questões que, a meu ver, a crítica não conseguiu avaliar com o devido destaque, porque seu instrumentário estava dirigido para outras áreas de produção artística.

Nas páginas que seguem mostramos obras recentes de pintores que atuam em São Paulo, e que chegaram a amadurecer sua linguagem ao longo desta década. Cada um dele possui um estilo próprio, bastante diferente dos demais. No entanto, há alguns traços em comum: todos eles trabalham com questões que dizem respeito à própria feitura da obra (linha, cor, matéria, sentido da superfície e ilusão de profundidade), criando relações que se resolvem dentro do plano do quadro, e independem da colocação do quadro no espaço. Em outras palavras, todos eles parecem preocupados em colocar e resolver problemas circunscritos num campo de ação autônomo e auto-suficiente - campo que se identifica, fisicamente, com a superfície do quadro e, idealmente, com o ofício de pintar.

Costumamos identificar essa reivindicação de autonomia com o conceito histórico de Modernismo, conceito que encontrou sua formulação mais forte e mais recente em Clement Greenberg. A idéia de que a arte precise definir claramente um campo autônomo de atuação, para exercer sua função crítica - idéia que é o cerne do pensamento modernista -, foi duramente criticada nos últimos 30 anos, e sobretudo na última década, a favor de uma concepção da arte mais aberta, indeterminada e "impura". Como interpretar, então, o ressurgir de comportamentos artísticos tipicamente modernistas, justamente agora, e justamente no Brasil? Uma primeira resposta poderia ser que, no Brasil, nunca existiu um campo específico da arte, sólido e claramente definido. A urgência de criá-lo, a partir de práticas próprias, irredutíveis a outros contextos, é portanto mais evidente entre nós do que em outros países, em que essa independência, pelo menos institucionalmente, parece garantida. A nova pintura, em suma, responderia à exigência de estabelecer uma forma mentis artística adequada, para alcançar finalmente uma modernidade sempre prometida e continuamente adiada.

Mas podemos ampliar a perspectiva: a década de 90 abriu-se na ilusão de que todas as grandes narrativas estivessem esgotadas. A hipótese do fim da história gerou naturalmente a hipótese do fim da arte: de fato, se a arte é fixação de um fato contingente irredutível a sistema, e se esse fato contingente não pode mais ser inserido numa narrativa, então a arte perde qualquer esperança de estabelecer um campo próprio de conhecimentos, que seja específico e relevante. Torna-se um aparato retórico, disponível para veicular um conteúdo qualquer. Nesse quadro, não faz muito sentido procurar os limites específicos de cada meio: quanto mais polivalentes e envolventes as obras, tanto mais persuasivo o discurso. Mas a década se fecha num clima, por assim dizer, de fim do fim da história - na sensação de que grandes questões, inclusive culturais, ainda não foram resolvidas. Parece-me que, nesse quadro, a tentativa de estabelecer uma área específica do saber estético possa voltar a ser relevante. Não surpreenderia, então, que esse esforço fosse mais evidente em países para os quais a história ainda deve muito.

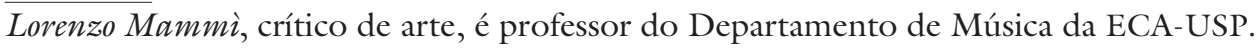




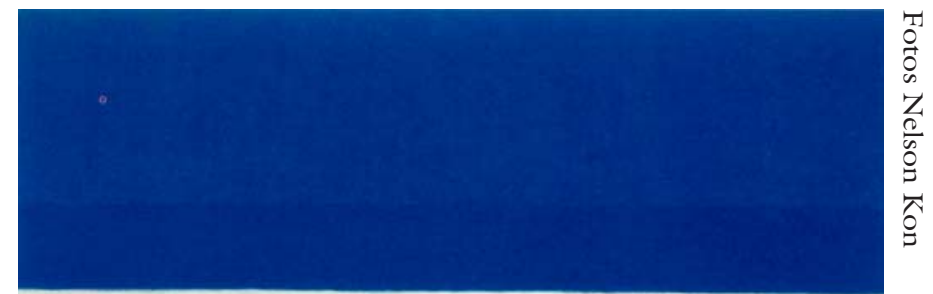

Renata Tassinari s/título, óleo s/tela, 1996, 150 x $150 \mathrm{~cm}$.

Renata Tassinari s/titulo, óleo s/tela, 1996, 120 x $80 \mathrm{~cm}$.

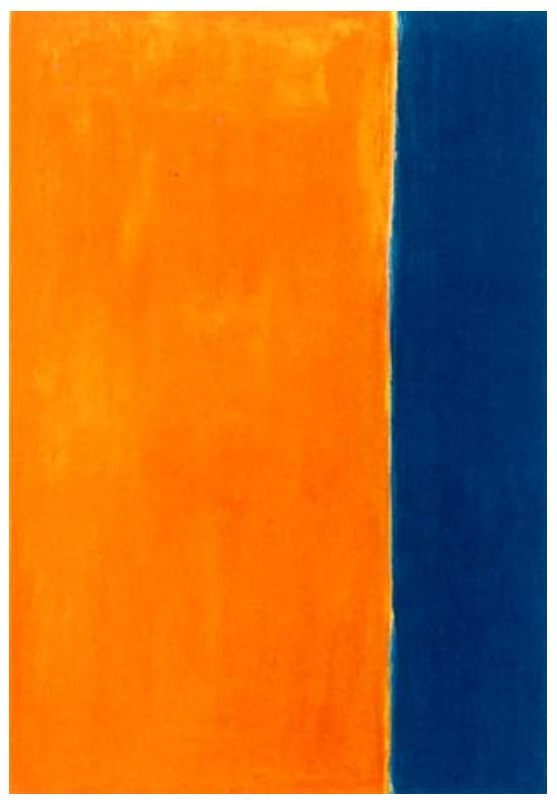




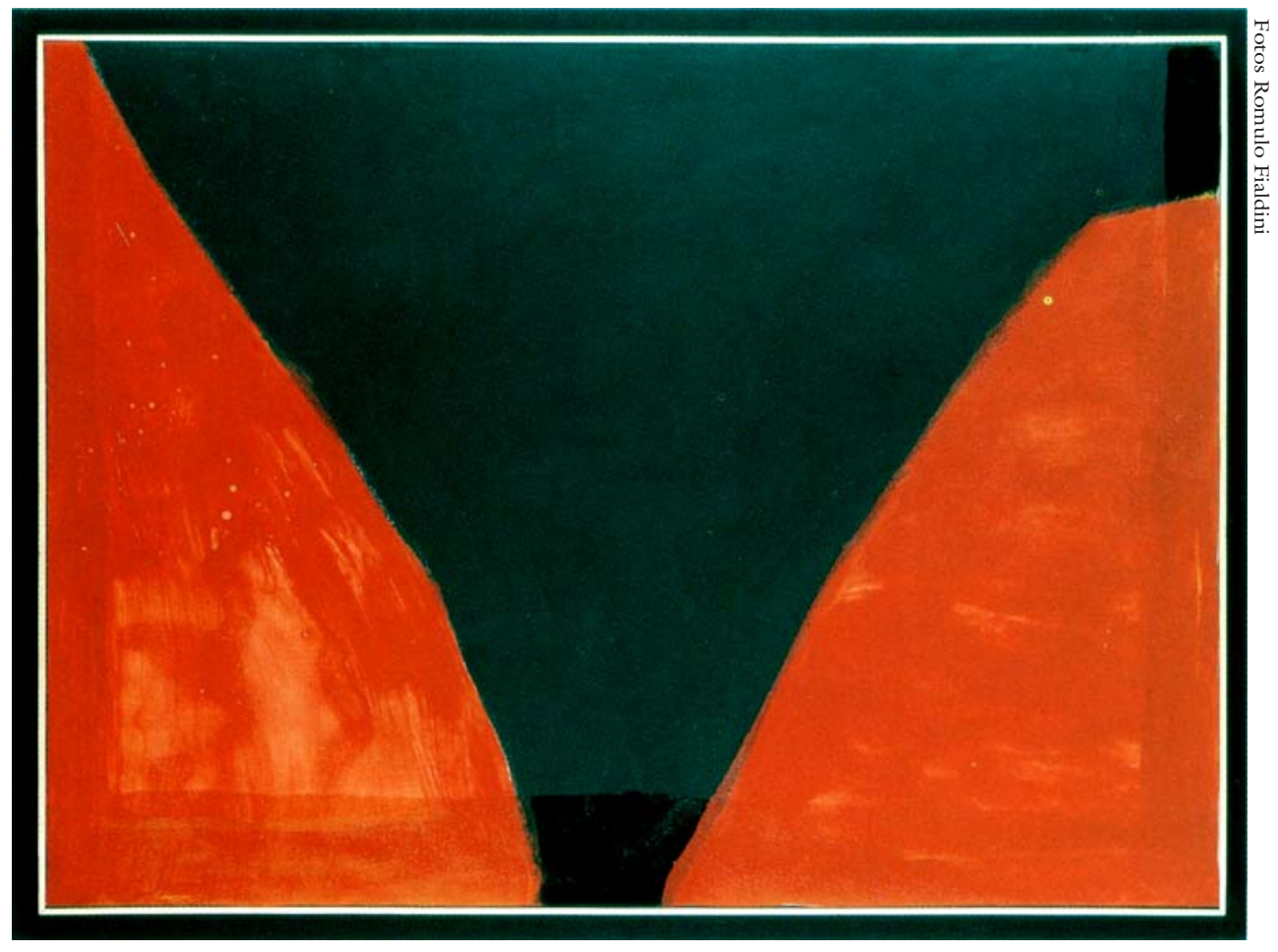

Salvio Daré s/título, óleo e esmalte s/papel, 1996, 100 x $100 \mathrm{~cm}$.

Salvio Daré s/título, esmalte e pigmentos s/papel, $1996,23,5 \times 32,5 \mathrm{~cm}$.

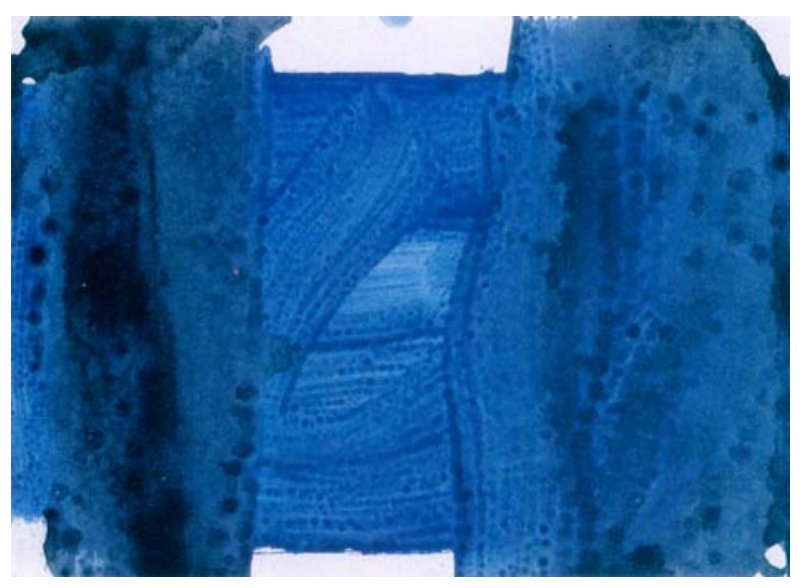




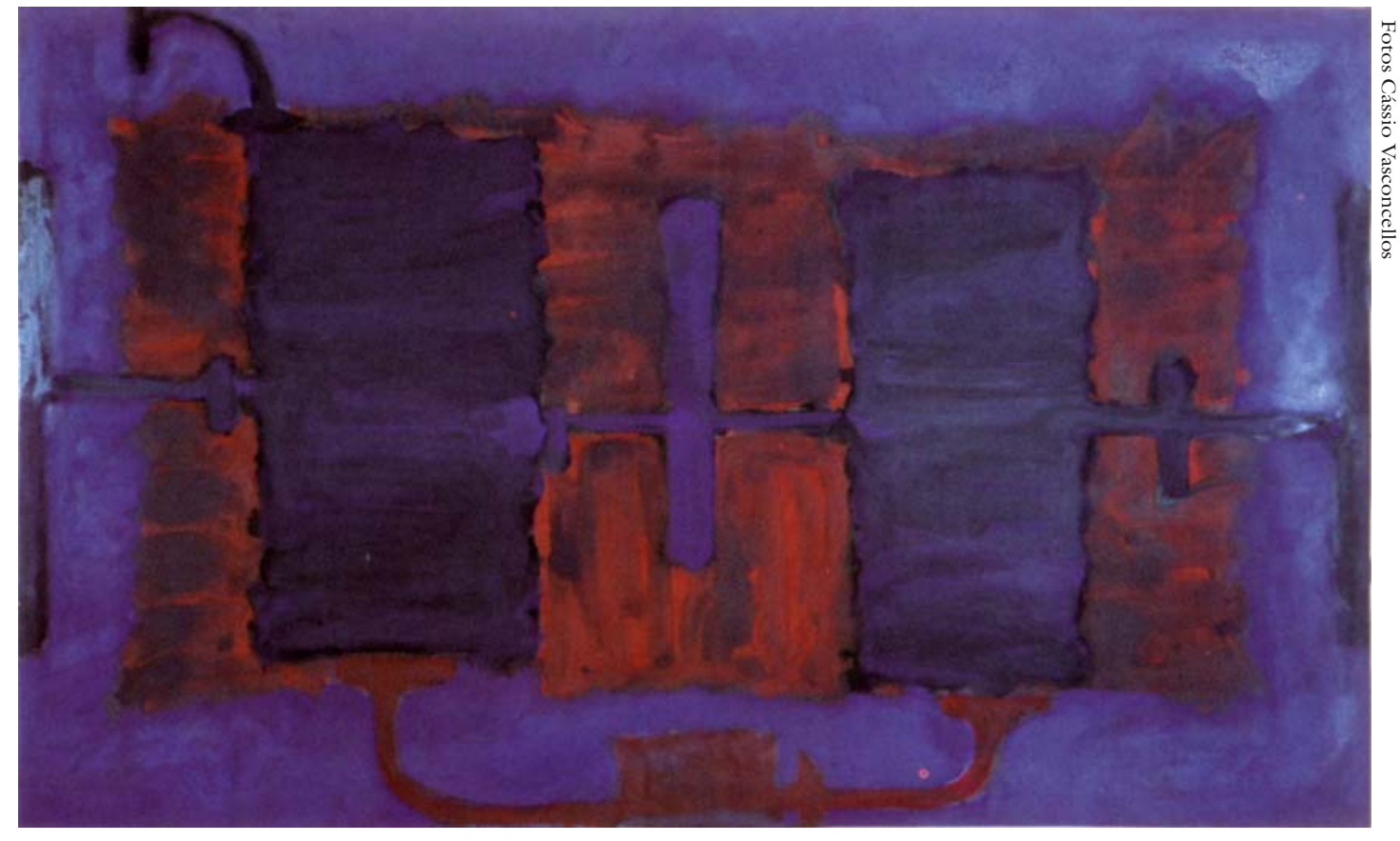

Marco Giannotti Cromo em violeta e marrom, témpera acrílica s/tela, 1997,170 x $280 \mathrm{~cm}$.

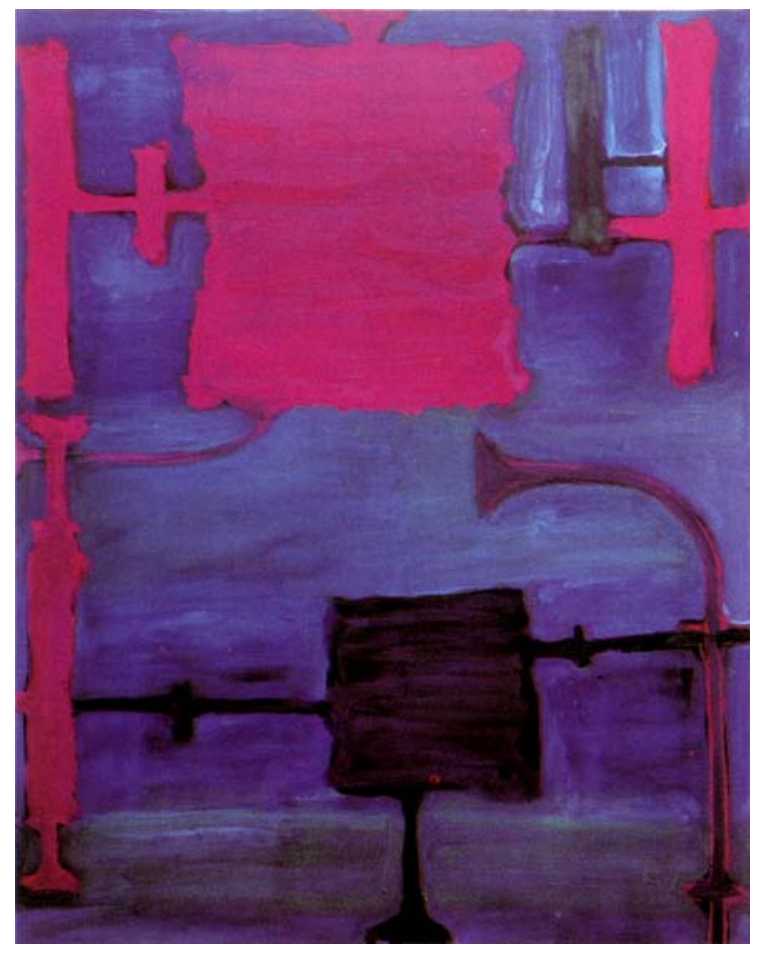

Marco Giannotti Cromo em rosa, violeta e verde, témpera acrílica s/tela, 1997, 260 x $210 \mathrm{~cm}$. 


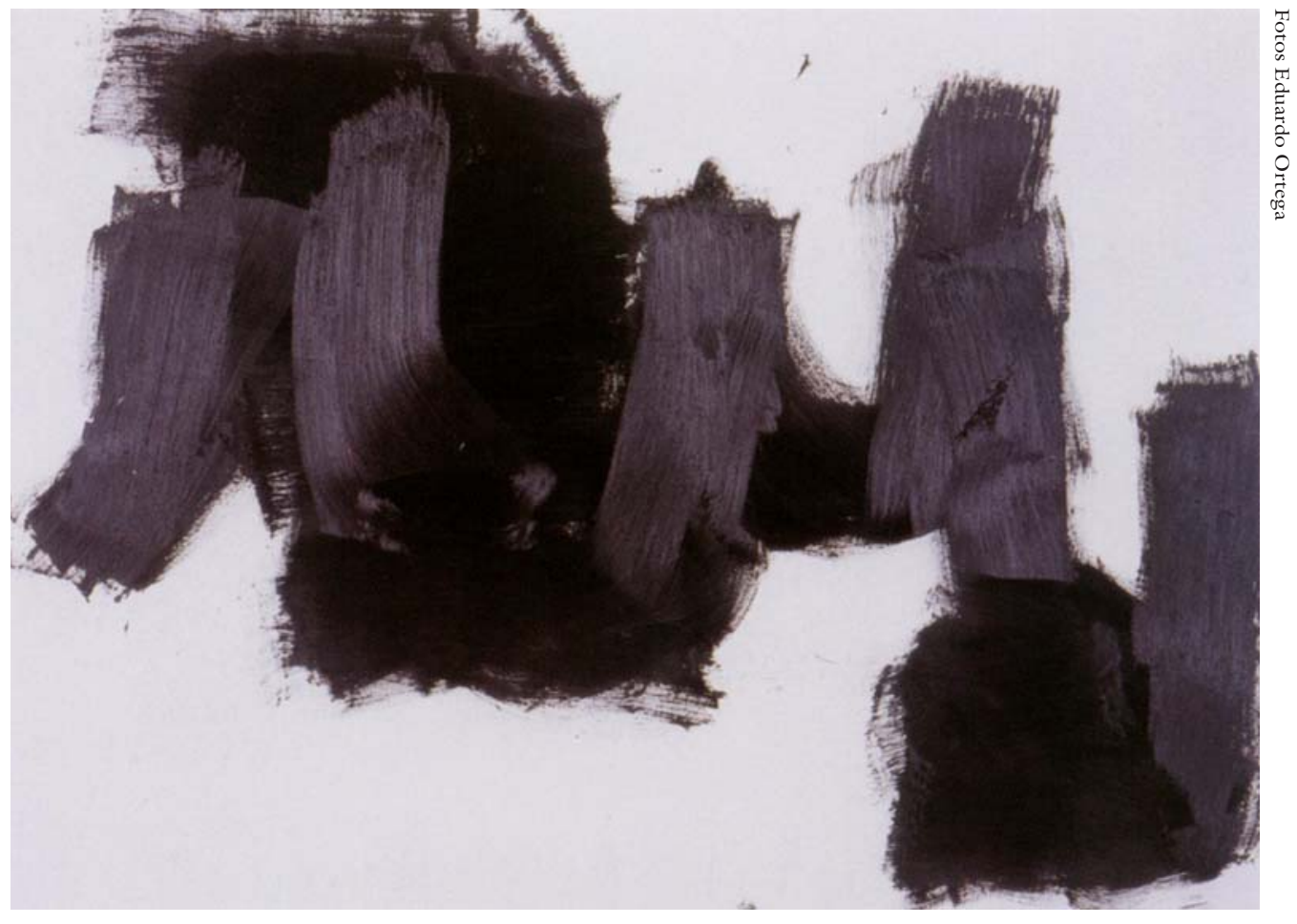

Célia Euvaldo s/título, óleo s/tela, 1997, 150 x $210 \mathrm{~cm}$.

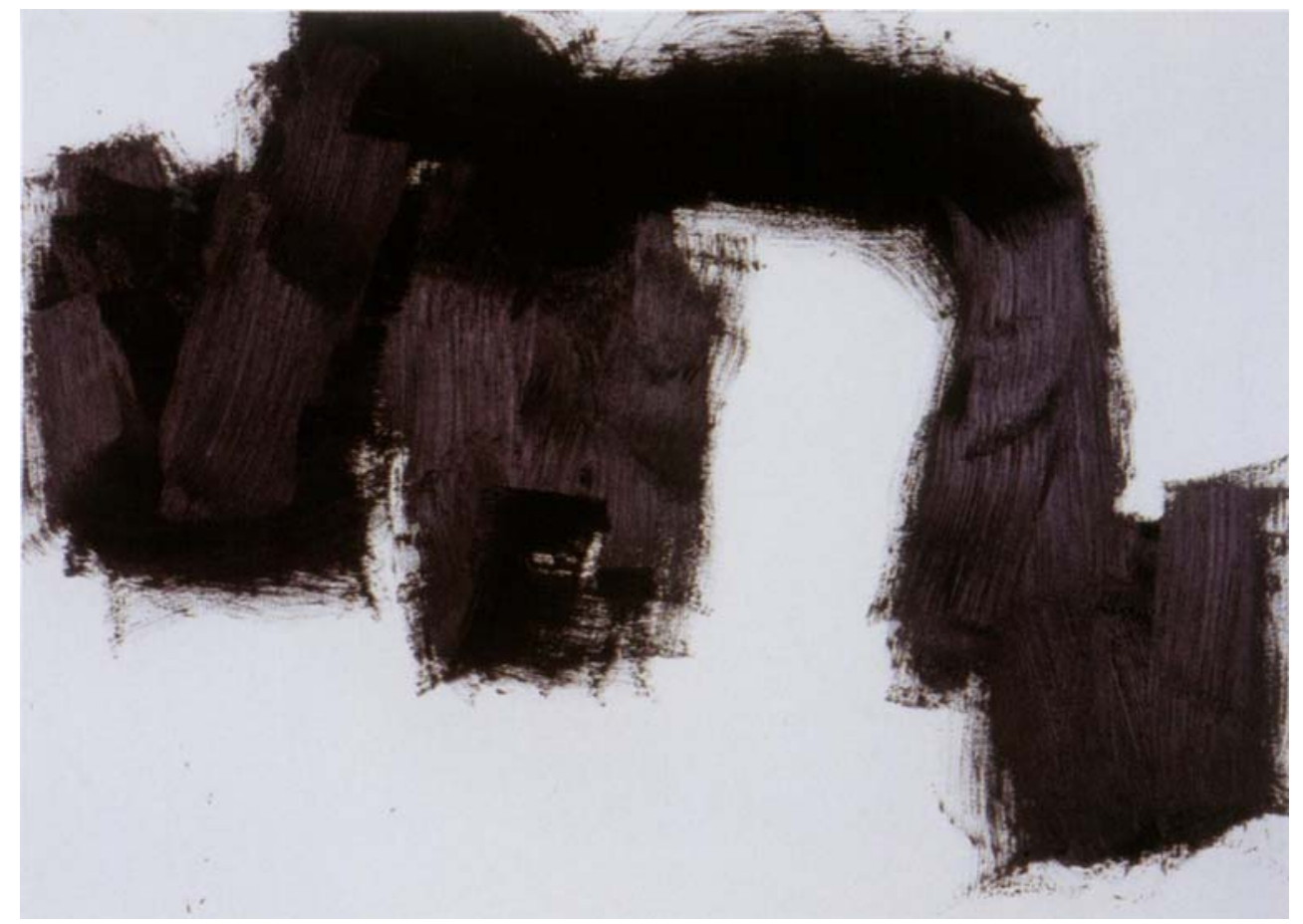

Célia Euvaldo s/título, óleo s/tela, 1997, 150 x $210 \mathrm{~cm}$. 


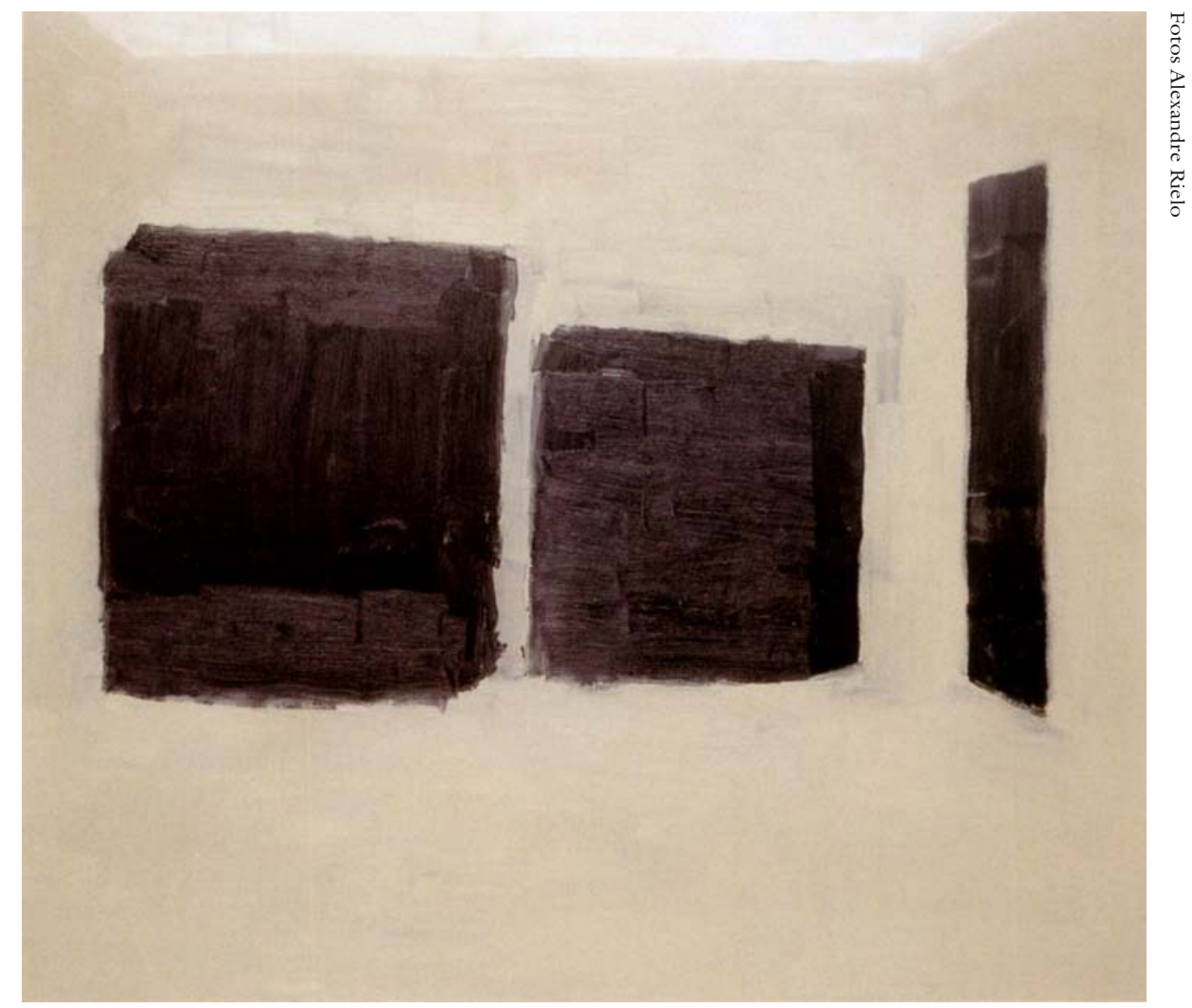

Rodrigo Andrade s/título, óleo s/tela, 1997, 190 x $220 \mathrm{~cm}$.

Rodrigo Andrade s/titulo, óleo s/tela, 1997, 30 × $35 \mathrm{~cm}$.

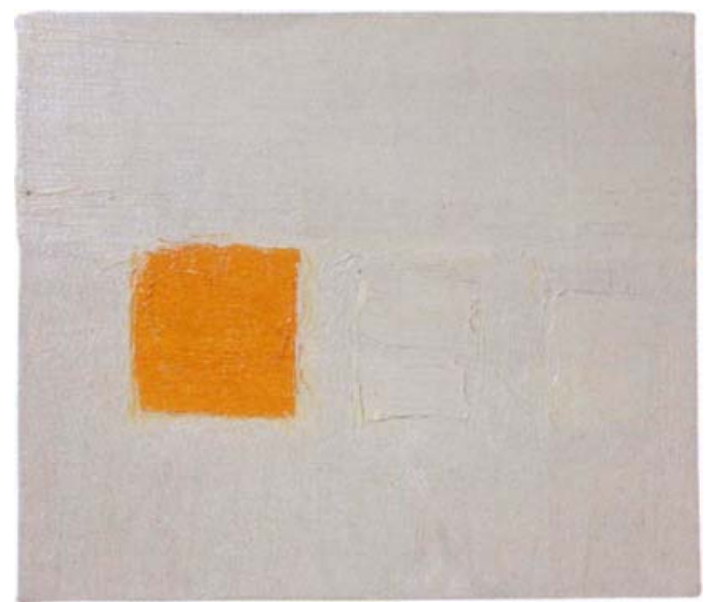

Estudos AvançAdos 12 (33), 1998 


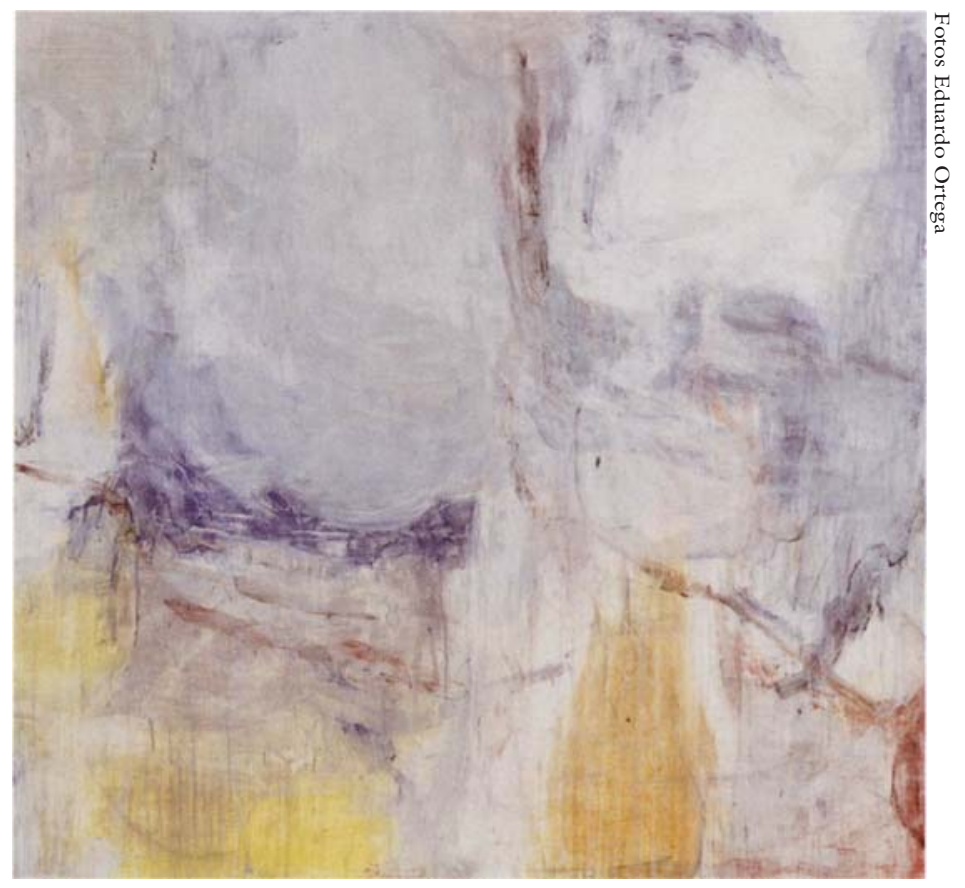

Fábio Miguez s/título, óleo e cera s/tela, 1997, 145 x $155 \mathrm{~cm}$.

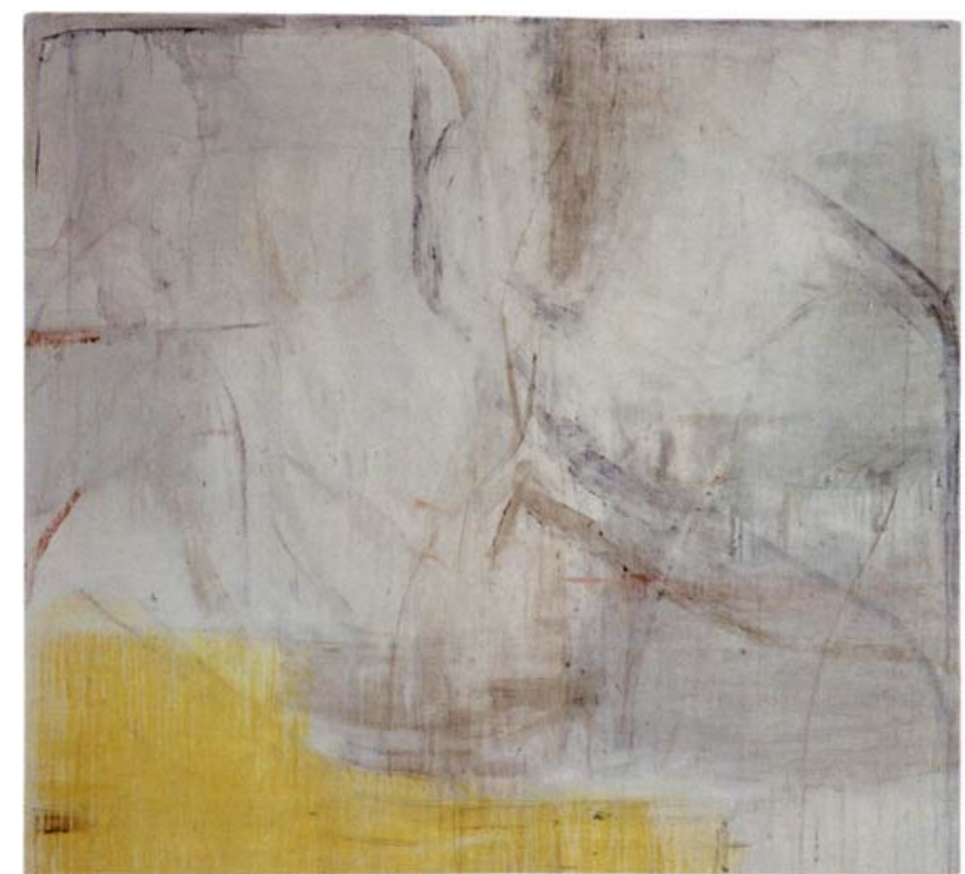

Fábio Miguez s/titulo, óleo e cera s/tela, 1997, 145 x $155 \mathrm{~cm}$. 